\title{
ENDOVASCULAR TREATMENT FOR INTERMITTENT CLAUDICATION IN PATIENTS WHO DO NOT IMPROVE WITH CLINICAL TREATMENT
}

Nelson Wolosker, Livio Nakano, Ruben Ayzin Rosoky, Marco Antonio Munia, Baptista Muraco Netto, and Pedro Puech-Leão

\begin{abstract}
Wolosker N, Nakano L, Rosoky RA, Munia MA, Muraco Netto B, Puech-Leão P. Endovascular treatment for intermittent claudication in patients who do not improve with clinical treatment. Clinics. 2005;60(3):193-200.
\end{abstract}

PURPOSE: To study the results including long-term follow-up obtained with endovascular treatment of patients with intermittent claudication who did not experience clinical improvement with conservative treatment.

METHODS: From January 1992 to January 2002, 62 of 1380 patients (4.5\%) with intermittent claudication underwent endovascular treatment and were followed up for up to 120 months (mean 76 months). The variables analyzed were the functioning of the arterial segment undergoing the endovascular procedure, the evolution of the maximum walking distance, and incidence of related morbidity and mortality.

RESULTS: Fifty-two patients (84\%) experienced no walking limitation after the procedure, and 6 patients (10\%) improved but still exhibited some degree of limitation, for a total improved outcome of $94 \%$. The patency rate was $82 \%$. There was no intraoperative mortality. One primary failure and one immediate thrombosis occurred, and both were surgically corrected. Thrombosis of the treated artery occurred in 6 patients 12, 16, 25, 29, 62, and 66 months after the procedure. These patients started to experience intermittent claudication with a walking distance to onset that was similar to their presurgical distance to onset. During follow-up, a mortality rate of $12.9 \%$ (8 patients) was observed, 6 due to myocardial infarctions and 2 due cerebral infarction. Three patients underwent coronary bypasses 22, 36, and 55 months after the endovascular surgery, and 2 patients underwent coronary angioplasty after 6 and 26 months. The mean follow up period was 76 months (range 0-120 months).

CONCLUSION: This study shows that endovascular treatment of intermittent claudication brought about a lasting regression of the ischemic conditions in a significant number of patients, with excellent patency rates. It was concluded that this is a good alternative for selected patients, with low rates of complications and positive long-term results.

KEYWORDS: Endovascular repair. Intermittent claudication. Clinical treatment. Stent. Angioplasty.

For patients with critical ischemia, revascularization is the procedure of choice for limb salvage. Endovascular procedures and arterial grafting are the prescribed methods. ${ }^{\mathbf{1 , 2}}$ For patients with intermittent claudication (IC), the goal of the treatment is the improvement of quality of life through increasing the walking distances.

The relatively benign natural evolution of $\mathrm{IC}^{3,4}$ and the dubious surgical results obtained in the 1960s and $1970 \mathrm{~s}^{5}$

Division of Vascular Surgery, Hospital das Clínicas, Faculty of Medicine, University of São Paulo - São Paulo/SP, Brazil.

E-mail: nwolosker@yahoo.com.br

Received for publication on July 29, 2004.

Accepted for publication on January 21, 2005. have justified conservative treatment for the majority of cases. Thus, in our service, a clinical approach has been used in the initial stage of treatment. After a period of physical training, the therapeutic response is evaluated. When a good response is not achieved and the patient is in good physical condition, revascularization is proposed, which allows for immediate benefits to be obtained. , $^{6}$

The use of endovascular surgery in cases of IC has been increasing progressively. However, there are few prospective studies that analyze its results among individuals who had not obtained improvement through clinical treatment, especially with long-term follow-up. 
The goal of this work was to prospectively study results obtained through endovascular treatment of patients with IC who did not gain sufficient clinical improvement via conservative treatment, including a long-term (76 months with a range of 0-120 months) follow-up.

\section{PATIENTS AND METHODS}

During the period from January 1992 to January 2002, 62 patients who underwent endovascular treatment for IC were followed up. These were a subset of a group of 1380 patients with this condition who were admitted during this period to an outpatient service for peripheral obstructive arterial disease and IC. The patients undergoing endovascular procedures represented $4.5 \%$ of the total.

All the patients treated in our service followed the sequence of therapeutic options presented in Figure 1.

The clinical approach (unsupervised physical training and treatment of the risk factors for peripheral obstructive arterial disease) was used in the initial phase of treatment. After a period of clinical treatment lasting for at least 6 months, the therapeutic response was analyzed. When the walking distance improved, the clinical treatment was maintained. If claudication worsened, or if no change was observed, patients were offered the options of maintaining clinical treatment or undergoing endovascular treatment (Figure 1).

\section{INTERMITTENT CLAUDICATION}
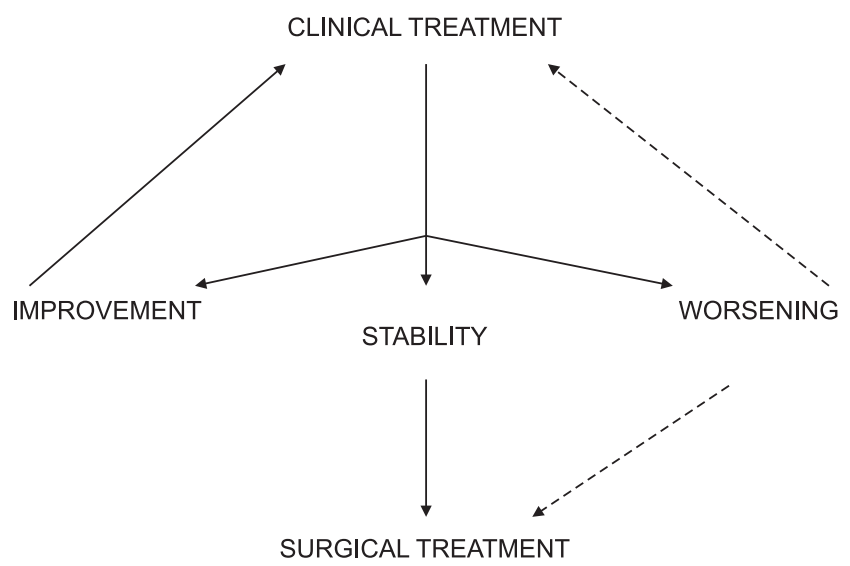

Natural (accepted) sequence of treatment.

Alternative sequences that may or may not be used.

Figure 1 - Treatment scheme for Intermittent Claudication.

As a result of this therapeutic strategy, only 380 (27.5\%) out of the 1380 patients treated for IC in our institution, experienced no increase in their walking distance capability after a minimum period of 6 months of unsupervised clini- cal treatment. Of these 380 patients with poor results, 55 (4\%) evolved to ischemia that threatened to produce limb loss, and for these, revascularization was formally indicated as a form limb saving therapy. For the remaining 325 (23.5\%), revascularization was suggested for improving the walking distances. The majority of these patients (237 or $17.2 \%$ ) preferred to continue with the clinical treatment because they did not want to run the risks inherent in the endovascular procedures, while the other $88(6.2 \%)$ decided to avail themselves of this alternative. Thus, 26 surgical procedures $(1.8 \%)$ and 62 endovascular procedures $(4.5 \%)$ were performed. It is the latter group that is presented in this study.

The 62 patients (48 male, 14 female) who underwent endovascular procedures, had an average age was 58.7 years (46 to 69 years); of these, $54(87.1 \%$ ) were smokers, 24 (40\%) were hypertensive, and $15(24 \%)$ were diabetic.

The average duration of the claudication, from its appearance until the time of the surgery was 22 months, with a range of 8 to 46 months.

No patient included in this study presented ischemic pain at rest, tissue loss, or gangrene of ischemic cause. The average ankle-arm index was 0.62 . No patient presented arterial pressure in tibial arteries lower than $40 \mathrm{~mm} \mathrm{Hg}$.

All the patients underwent preoperative digital arteriography or angioresonance to determine the type of arterial revascularization to be employed in each case. Endovascular procedures were performed on the patients who presented obstructive disease in aortoiliac arterial segments of lengths shorter than $5 \mathrm{~cm}$ and in femoropopliteal arterial segments of lengths shorter than $3 \mathrm{~cm}$. Patients who presented lesions of lengths greater than $5 \mathrm{~cm}$ were treated by surgical bypasses and are not included in this study. Aortoiliac disease was observed in 52 patients and femoropopliteal disease in 10 .

To objectively assess the severity of IC, we measured the maximum walking distance (MWD) using a progressive treadmill test. This was done at a constant velocity of 3.2 $\mathrm{km} / \mathrm{hr}$, initially on level ( 0 degrees), then with a progressive increase of $2 \%$ in the inclination every 2 minutes. The test was performed until pain prevented the patient from continuing to walk, and this value was also kept as comparison standard for the follow-up period. ${ }^{8}$ The average MWD before surgical treatment was $160 \mathrm{~m}$ (range: 50 to $200 \mathrm{~m}$ ) for this sample of patients.

The vascular evolution was determined through periodic measurements of the walking distance values obtained in equivalent treadmill tests performed at every return visit. The evolution was considered to be favorable when there was an increase of more than 50 meters in the distance walked. The remaining cases were considered to present unfavorable evolution. 
The endovascular procedures employed are shown in Table 1 .

Table 1 - Procedures performed.

\begin{tabular}{lc}
\hline Procedures & Number of Patients \\
\hline Uni-iliac stent & 44 \\
Aortic stent & 3 \\
Bi-Iliac stent & 5 \\
Femoro-popliteal stent & 10 \\
Total & 62 \\
\hline
\end{tabular}

All procedures were performed in the operating room under epidural anesthesia. For the uni-iliac procedure, access was gained by ipsi-lateral retrograde puncture, except in 1 patient who underwent open access arterial surgery. For the aortic and bi-iliac procedures, bilateral retrograde puncture was used. For the femoro-popliteal procedures, anterograde puncture of the common femoral artery was used, except in 1 patient for whom it was suspected that arterial dissection on the same side would be required. In this case, inguinotomy and direct exposure of the common femoral artery was the chosen approach.

After placement of the guidewire, a 7F catheter was inserted so intravenous anticoagulant heparin therapy could be administered. After crossing the lesion with the guidewire, we dilated the lesion with a balloon and then placed the stent. In all cases we used the Palmaz stent. Angiographies were performed immediately before and after balloon dilation and after placement of the stent.

All patients, except 2 who had complications, were discharged 1 day after the procedure. The 2 patients with complications were discharged after 10 and 27 days.

All patients were treated with antiplatelet agents after the procedure (AAS $100 \mathrm{mg} /$ day or ticlopidine $500 \mathrm{mg} /$ day), and de-ambulation was recommended.

Patients were reevaluated after 3 months and 6 months, and at 6 months intervals thereafter. The follow-up duration ranged from 9 to 114 months, with an average of 76 months. At each visit, the treadmill test was performed and the MWD was determined. The patency of the treated arterial segments that underwent angioplasty and stent deployment was confirmed by means of physical examination and color duplex sonography.

The variables analyzed were the functioning of the arterial segment that underwent the endovascular procedure, the evolution of the MWD, patency, morbidity, and mortality.

\section{RESULTS}

There was 1 primary failure, in a patient who underwent iliac stent insertion. The patient immediately underwent an iliac-femoral bypass with good clinical results.

There was 1 immediate thrombosis in a patient who underwent a uni-iliac stent procedure. This patient immediately underwent femorofemoral bypass, but she developed ischemic gangrene and finally underwent amputation below the knee.

There were no other cases of worsening of the degree of ischemia, nor were there any intraoperative deaths in this group.

Fifty-two patients had no remaining walking limitation after the procedure (i.e. they were able to complete a distance of $1000 \mathrm{~m}$ in the treadmill test). Six patients experienced significant improvement, although with some degree of limitation (i.e. they achieved $420 \pm 150 \mathrm{~m}$ in the treadmill test), and 4 presented a small improvement in their maximum walking distance (less than 50 meters). Thus, 58 patients presented favorable evolution, and only 4 had unfavorable evolution.

During the follow-up, 6 patients presented thrombosis of the treated artery, which occurred 12, 16, 25, 29, 62, and 66 months after the procedure. After their occlusions, these patients started to suffer from IC with onset at presurgical distances. These patients were walking distances that did not inhibit their basic activities. We observed relapse to previous claudication levels in 3 other patients due to disease progression in the femoropopliteal segment. These occurred in patients who had previously undergone iliac stent insertion.

The overall mortality rate including the follow-up period was $12.9 \%$. Six patients suffered acute myocardial infarctions 21, 26, 29, 36, 48, and 68 months after the endovascular procedure, and died. Two patients died because of cerebral infarction 32 and 52 months after the endovascular procedure.

Regarding morbidity, 3 patients underwent coronary bypass surgery 22, 36, and 55 months after the endovascular surgery, and 2 patients underwent coronary angioplasty 6 and 26 months after surgery. One patient had a cerebral infarct 39 months after the procedure with total clinical regression, and 1 patient has been undergoing dialysis which started 38 months after the procedure.

The results of the long-term patency are shown in Table 2 and Figure 2 .

\section{DISCUSSION}

At the beginning of the revascularization era in the 1960s and 1970s, it was thought that the natural evolution of IC would be an inexorable progression of ischemia until consequent loss of the limb, which appeared to justify early 
Table 2 - Long-term cumulative primary patency of endovascular procedures

\begin{tabular}{|c|c|c|c|c|c|c|c|c|}
\hline \multirow[b]{2}{*}{ Interval (months) } & \multirow[b]{2}{*}{ At risk } & \multirow{2}{*}{\multicolumn{2}{|c|}{$\begin{array}{c}\text { No of patients } \\
\text { Deaths }\end{array}$}} & \multirow[b]{2}{*}{ Withdrawn } & \multirow[b]{2}{*}{ Lost/Total } & \multirow[b]{2}{*}{ Interval } & \multirow{2}{*}{$\begin{array}{c}\text { Patency } \\
\text { Cumulative }\end{array}$} & \multirow[b]{2}{*}{ Standard Error } \\
\hline & & & & & & & & \\
\hline $0-1$ & 62 & 2 & 0 & 0 & 0 & 96.8 & 96.8 & 0.0221 \\
\hline $1-3$ & 60 & 0 & 0 & 1 & 0 & 100.0 & 96.8 & 0.0225 \\
\hline $4-6$ & 59 & 0 & 0 & 2 & 0 & 100.0 & 96.8 & 0.0228 \\
\hline $7-12$ & 57 & 1 & 0 & 2 & 0 & 98.2 & 95.0 & 0.0283 \\
\hline $13-18$ & 54 & 1 & 0 & 1 & 0 & 98.1 & 93.3 & 0.0331 \\
\hline $19-24$ & 52 & 0 & 1 & 1 & 0 & 100.0 & 93.3 & 0.0339 \\
\hline $25-30$ & 50 & 2 & 2 & 0 & 0 & 95.9 & 89.5 & 0.0415 \\
\hline $31-36$ & 46 & 0 & 2 & 3 & 0 & 100.0 & 89.5 & 0.0440 \\
\hline $37-42$ & 41 & 0 & 0 & 5 & 0 & 100.0 & 89.5 & 0.0468 \\
\hline $43-48$ & 36 & 0 & 2 & 0 & 1 & 100.0 & 89.5 & 0.0494 \\
\hline $49-54$ & 33 & 0 & 0 & 2 & 1 & 100.0 & 89.5 & 0.0517 \\
\hline $55-60$ & 30 & 0 & 0 & 4 & 1 & 100.0 & 89.5 & 0.0554 \\
\hline $61-66$ & 25 & 1 & 0 & 1 & 0 & 95.9 & 85.8 & 0.0653 \\
\hline $67-72$ & 23 & 1 & 1 & 0 & 0 & 95.6 & 82.0 & 0.0733 \\
\hline $73-78$ & 21 & 0 & 0 & 0 & 0 & 100.0 & 82.0 & 0.0809 \\
\hline $79-84$ & 16 & 0 & 0 & 5 & 0 & 100.0 & 82.0 & 0.0914 \\
\hline $85-90$ & 13 & 0 & 0 & 3 & 0 & 100.0 & 82.0 & 0.0984 \\
\hline $91-96$ & 12 & 0 & 0 & 1 & 0 & 100.0 & 82.0 & 0.1129 \\
\hline $97-102$ & 7 & 0 & 0 & 4 & 1 & 100.0 & 82.0 & 0.1483 \\
\hline $103-108$ & 4 & 0 & 0 & 3 & 0 & 100.0 & 82.0 & 0.1740 \\
\hline $109-114$ & 4 & 0 & 0 & 0 & 0 & 100.0 & 82.0 & 0.2200 \\
\hline $115-120$ & 1 & 0 & 0 & 3 & 0 & 100.0 & 82.0 & 0.3479 \\
\hline $121-126$ & 1 & 0 & 0 & 0 & 0 & 100.0 & 82.0 & 0.3479 \\
\hline
\end{tabular}

Life Table

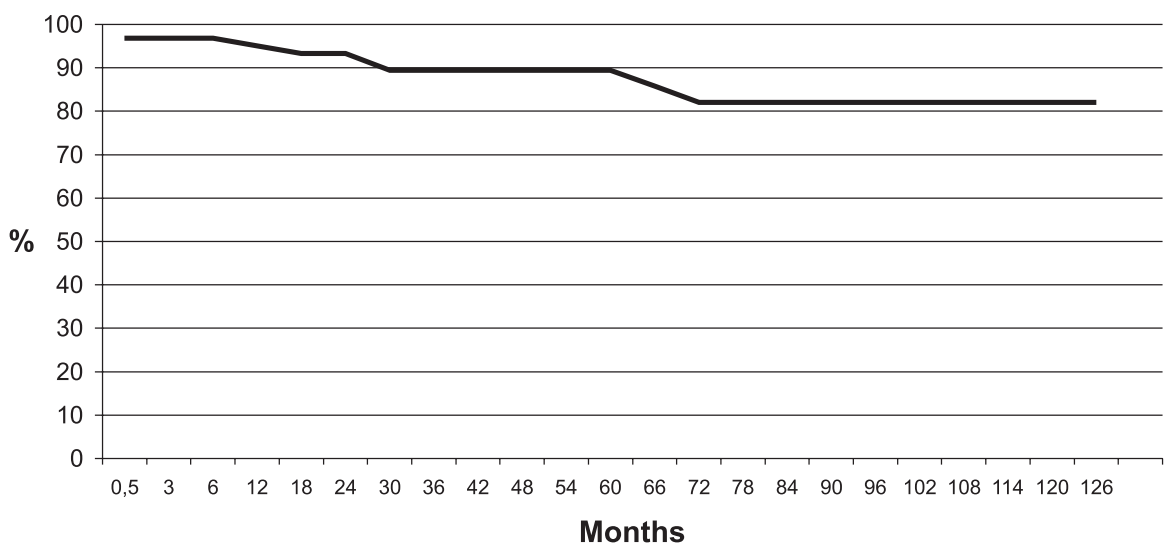

Figure 2 - Cumulative primary patency rates of 62 consecutive angioplasties performed for intermittent claudication.

surgical treatment. However, the surgical techniques and equipment available at that time were less developed than those of today, and results were debatable..$^{5}$ Although the risk of limb loss with conservative treatment does exist, studies using large samples have demonstrated that this progression is unusual. Boyd et al. studied 1440 patients with IC and reported that, after 10 years, $12.2 \%$ had required amputation. ${ }^{9}$ In the Framingham study, only $1.6 \%$ of claudication patients required amputation within a period of 8.3 years. ${ }^{10}$

Since patients treated clinically were being seen to present low amputation rates, the clinical approach came to be used with more confidence, safety, and frequency from the 1970 s onwards, ${ }^{3}$ thus relegating surgical treatment to a secondary position.

Reduction in the risk of limb loss has ceased to be the main objective of treatment. In fact, the objective has shifted to improvement of the quality of life of IC sufferers by reducing their physical limitations while always respecting the risks and benefits of each procedure. ${ }^{11}$

On the basis of this notion, our service began to use the sequence of therapeutic options presented in Figure 1.

Since 1964, when Dotter et al. ${ }^{12}$ performed the first angioplasties in the femoropopliteal region using rigid 
metal catheters, a new set of endovascular procedures that provide an alternative to conventional arterial surgery for the treatment of arterial obstructions has been developed. ${ }^{13}$ The first type of endovascular treatment used was angioplasty. Despite being conceptualized in the 1960s, angioplasty only became an applicable technique from the 1970s onwards, with the introduction of the balloon catheters devised by Gruntzig. ${ }^{14}$. In this procedure, a balloon is inserted into the artery and positioned precisely over the atherosclerotic plaque. By insufflation of the balloon, the stenotic plaque is ruptured and partially separated from the vascular wall, thereby resulting in a significant increase in the arterial lumen.

Technological advances achieved over recent decades, comprise improvements in the acquisition of vascular imaging and the development of new catheters, drugs, and complementary accessories for angioplasty. Such accessories include thrombolytic agents, stents, and endoprostheses that can be used for improving the results of angioplasty. ${ }^{15,16}$

At present, angioplasty and stent angioplasty are the endovascular procedures most frequently used in patients with localized obstructive arterial lesions in the aortoiliac segment. We have opted for the second option from the start of this study, because we believe in the advantages of stenting angioplasty, as evidenced in the TransAtlantic Inter-Society Consensus ${ }^{17}$. Meanwhile, angioplasty is also a good option.

In our sample, we observed that $83.8 \%$ of the patients presented aortoiliac disease, and only $16.2 \%$ presented disease in the infra-inguinal segment. This is due to the fact that endovascular revascularization in more proximal (aortofemoral) segments favors a good evolution, ${ }^{18}$ which is why endovascular revascularization of the more proximal aortofemoral segments is indicated more frequently. In femoropopliteal obstructive arterial disease, it has been demonstrated that angioplasties associated with stent placement above the knee in very short lesions (less than $3 \mathrm{~cm}$ ) have good results. ${ }^{2}$

Endovascular techniques and materials have undergone great improvements over the years. This has allowed improvements in the immediate and long-term results, as is evident in the literature in general, ${ }^{2,19}$ as well as in our sample, in which we had primary failure in only 2 cases (3.2\%) and a patency rate of $82 \%$ after an average of 76 months of follow-up.

With respect to evolution, attention must be paid to late obstructive complications. Non-obstructive complications are not frequent and have not yet been seen in our sample. The fact that only 1 patient from our sample had critical ischemia suggests that these were patients with less severe arterial disease and better prognosis, rather than the more compromised type of patient that has severe clinical manifestations. On the other hand, since all the operations in this study were performed on an elective basis, all our patients were submitted to surgery their best possible clinical conditions.

Atherosclerotic disease progression is a significant reason for the recurrence of ischemic symptoms in the lower limbs. ${ }^{20}$ In our series, even with the control of risk factors and a close follow-up, 6 patients $(9.6 \%)$ presented thrombosis in the treated artery, and 3 other patients $(4.8 \%)$ presented distal occlusions, probably because of the longer follow-up period, which had allowed evolution of the atherosclerotic disease.

Despite the fact that such patients are considered to present moderate surgical risk, we did not observe intraoperative mortality among this sample, probably because endovascular procedures are less invasive than conventional surgery. On the other hand and in conformity with other samples, ${ }^{21}$ we observed a mortality rate of $12.9 \%$ over our average follow-up time of 76 months. The main cause of death was acute myocardial infarct $(9.6 \%)$. In addition to this, 5 patients $(8.0 \%)$ underwent cardiac revascularization during this period. These data confirm data found other reports and also confirm the consensus that occlusive disease of the lower limbs is an important marker for associated coronary disease. ${ }^{22}$

The treatment of IC has been evolving and is being refined with knowledge of its natural history through the use of different physical training techniques, surgical techniques, and endovascular techniques that are steadily becoming more developed.

The clinical approach (physical training) has in its favor its noninvasive nature, with a low incidence of complications, ${ }^{23-26}$ as well as its systemic action. It tends to improve walking distance capability in a slow and gradual manner, bringing benefits to the whole cardiovascular system and interrupting or at least diminishing the progression of the atherosclerotic disease. ${ }^{4,27-31}$ Nonetheless, to obtain the desired effect, great effort is required from the patient, and treatment takes a long time.

The endovascular approach is defensible because of its immediate benefits. ${ }^{32,33}$ In our sample, $93.5 \%$ of the patients presented immediate improvement in their symptomatology after the surgical procedure. From a socioeconomic point of view, the rapid reintegration of patients into their habitual activities, including work, and especially among younger patients, justifies the adoption of this type of therapy more frequently. ${ }^{34}$ Another advantage of endovascular treatment is the benefit enjoyed by patients during the period while they are free from late complications. These patients enjoy a good quality of life beginning in their postoperative pe- 
riod and extending until late-stage cardiovascular events occur, which took place in $24.2 \%$ of our sample of patients.

Available published data combined to our personal experience over the last 10 years has allowed us to give patients with IC up-to-date information regarding their prognosis, with a comfortable safety margin. On the other hand, the results from the present study and those from other studies regarding endovascular treatment of IC lead to the conclusion that this is a very mature option, as a result of the sophistication and refinement of techniques and technologies. ${ }^{24,25,35}$ Although the indication for endovascular surgery for IC is still the exception, the results contrast greatly with those of earlier years that led to the relegation of surgical treatment to a secondary position.

In making a detailed analysis of our sample, it can be noted that only the patients with an unsatisfactory response to clinical treatment underwent endovascular treatment. Thus, these patients possibly had a worse prognosis than those that responded well to clinical treatment. It is possi- ble that the patients who underwent surgical treatment presented arterial margins that were more compromised, disease of a more aggressive character, or muscle conditions that were less favorable than those present in the patients who improved with clinical treatment. Thus, considering the good results obtained with this sample, we may infer that the surgical treatment of patients who do not necessarily present improvement with clinical treatment will possibly bring results that are equal to or even more promising than clinical treatment. We believe that the role of endovascular surgery in the treatment of IC must be reconsidered in the sense of expanding its coverage.

In our study, the results from endovascular treatment of IC brought about a lasting regression of the ischemic conditions in a significant number of patients, with excellent patency rates. We conclude that this is a good alternative for selected patients, with low rates of complications and positive long-term results.

\section{RESUMO}

Wolosker N, Nakano L, Rosoky RA, Munia MA, Muraco Netto B, Puech-Leão P. Tratamento endovascular para pacientes portadores de Claudicação Intermitente que não melhoram com tratamento clínico. Clinics. 2005;60(3):193-200.

OBJETIVO: Estudar a longo prazo (média de 76 meses de seguimento) os resultados obtidos com o tratamento endovascular em pacientes que não melhoram com o tratamento clínico,

MÉTODOS: De Janeiro de 1992 a Janeiro de 2002, 62 pacientes de um grupo de 1380 claudicantes foram submetidos a tratamento endovascular, representando $4,5 \%$ do total. As variáveis analisadas foram o funcionamento do segmento arterial submetido ao procedimento endovascular, a evolução da distância máxima de marcha e a ocorrência de morbi-mortalidade.

RESULTADOS: Cinqüenta e dois (84\%) pacientes não apresentaram restrições à deambulação após o procedimento. Seis pacientes melhoraram, representando um benefício de 94\%. Não houve mortalidade intra-operatória. Uma falên- cia primária e uma trombose imediata foram corrigidas cirurgicamente. Seis pacientes apresentaram trombose da artéria tratada 12, 16, 25, 29, 62 e 66 meses após o procedimento e voltaram a apresentar Claudicação Intermitente para as mesmas distâncias referidas antes da cirurgia. Durante o seguimento foi observada taxa de mortalidade de $12,9 \%$ (8 pacientes), dos quais 6 por infarto do miocárdio e dois por acidente vascular cerebral. Três pacientes foram submetidos à revascularização miocárdica 22,36 e 55 meses após o procedimento endovascular e duas angioplastias foram realizadas com 6 e 26 meses de seguimento. O tempo médio de segmento foi de 76 meses ( 0 a 120 meses).

CONCLUSÃO: O tratamento endovascular da Claudicação Intermitente levou a melhora das condições da marcha em um número significativo de pacientes, com excelentes taxas de patência $(82,0 \%)$. Concluímos que esta é uma boa alternativa para determinados pacientes, com poucas complicações e resultados positivos a longo prazo.

UNITERMOS: Tratamento endovascular. Claudicação Intermitente. Tratamento clínico. Stent. Angioplastia. 


\section{REFERENCES}

1. Jamsen T, Tulla H, Manninen H, Raisanen H, Lahtinen S, Aittola V, et al. Results of infrainguinal bypass surgery: an analysis of 263 consecutive operations. Ann Chir Gynaecol. 2001;90(2):92-9.

2. Wolosker N, Nakano L, Anacleto MM, Puech-Leão P. Primary utilization of stents in angioplasty of superficial femoral artery. Vasc Endovascular Surg. 2003 Jul-Aug;37(4):271-7.

3. Imparato AM, Kim GE, Davidson T, Crowley JG. Intermittent claudication: its natural course. Surgery. 1975;78(6):795-9.

4. Wolosker N, Nakano L, Rosoky RA, Puech-Leão P. Evaluation of walking capacity over time in 500 patients with intermittent claudication who underwent clinical treatment. Arch Intern Med. 2003 Oct 27;163(19):2296-300

5. Peabody CN, Kannel WB. Intermittent claudication: surgical significance. Arch Surg. 1974;109:693-7.

6. Ernst E, Fialka V. A review of the clinical effectiveness of exercise therapy for intermittent claudication. Arch Intern Med. 1993;153(20):2357-60.

7. Regensteiner JG, Hargarten ME, Rutherford RB, Hiatt WR. Functional benefits of peripheral vascular bypass surgery for patients with intermittent claudication. Angiology. 1993;44(1):1-10.

8. Gardner AW, Skinner JS, Cantwell BW, Smith K. Progressive vs. single-stage treadmill tests for evaluation of claudication. Med Sci Sports Exerc. 1991;23:402-8.

9. Boyd AM. The natural course of arteriosclerosis of the lower extremities. Angiology. 1960;11:10-14.

10. Kannel WB, McGee DL. Update on some epidemiologic features of intermittent claudication: The Framingham Study. J Am Geriatr Soc. $1985 ; 33(1): 13-8$.

11. Brazier JE, Harper R, Jones NM, O'Cathain A, Thomas KJ, Usherwood T, et al. Validating the SF-36 health survey questionnaire: new outcome measure for primary care. BMJ. 1992;305(6846):160-4

12. Dotter CT, Judkins MP. Transluminal treatment of atherosclerotic obstruction: description of a new technique and a preliminary report of its application. Circulation. 1964;30:654-670.

13. Veith FJ, Marin ML. Endovascular technology and its impact on the relationships among vascular surgeons, interventional radiologists, and other specialists. World J Surg. 1996;20(6):687-91.

14. Gruntzig A, Hopff $\mathrm{H}$. Percutaneous recanalization after chronic arterial occlusion with a new dilator-catheter. Dtsch Med Wochenschr. 1974;99(49):2502-10, 2511.

15. Puech-Leão $P$, Kaufmann $P$, Wolosker $N$, Anacleto $A M$. Endovascular grafting of a popliteal aneurysm using the saphenous vein. J Endovasc Surg. 1998;5:64-70.

16. Cragg AH, Dake MD. Treatment of peripheral vascular disease with stent-grafts. Radiology. 1997;205(2):307-14.

17. TransAtlantic Inter-Society Consensus Working Group. Management of Peripheral Arterial Disease B 4.3 Endovascular Procedures for Intermittent Claudication. J Vasc Surg. 2000,Jan, 31(1 pt 2):S97-S111.
18. van Andel GJ, van Erp WF, Krepel VM, Breslau PJ. Percutaneous transluminal dilatation of the iliac artery: long-term results. Radiology. 1985;156,321-3.

19. White GH, Liew SC, Waugh RC, Stephen MS, Harris JP, Kidd J, et al. Early outcome and intermediate follow-up of vascular stents in the femoral and popliteal arteries without long-term anticoagulation. J Vasc Surg. 1995;21:270-281.

20. Wolosker N, Rosoky RA, Nakano L, Basyches M, Puech-Leão P. Predictive value of the ankle-brachial index in the evaluation of intermittent claudication. Rev Hosp Clin Fac Med São Paulo. 2000;55(2):61-4.

21. Schmieder FA, Comerota AJ. Intermittent claudication: magnitude of the problem, patient evaluation, and therapeutic strategies. Am J Cardiol. 2001;Jun28;87(12A):3D-13D.

22. Cooperman M, Pflug B, Martin EW Jr, Evans WE. Cardiovascular risk factors in patients with peripheral vascular disease. Surgery. 1978;84(4):505-9.

23. Boyd AM. The natural course of arteriosclerosis of the lower extremities. Angiology. 1960;11:10-14.

24. Keefer A, Davies MG, Illig KA. Can endovascular therapy of infrainguinal disease for claudication be justified? Expert Rev Cardiovasc Ther. 2004;2(2):229-37

25. Kalbaugh CA, Taylor SM, Cull DL, Blackhurst DW, Gray BH, Langan EM 3rd, Dellinger MB, McClary GE Jr, Jackson MR, Carsten CG 3rd, Snyder BA, York JW, Youkey JR. Invasive treatment of chronic limb ischemia according to the Lower Extremity Grading System (LEGS) score: a 6-month report. J Vasc Surg. 2004;39(6):1268-76

26. Costanza MJ, Queral LA, Lilly MP, Finn WR. Hemodynamic outcome of endovascular therapy for TransAtlantic InterSociety Consensus type B femoropopliteal arterial occlusive lesions. J Vasc Surg. 2004;39(2):343-50

27. Ekroth R, Dahllof AG, Gundevall B, Holm J, Schersten T. Physical training of patients with intermittent claudication: indications, methods, and results. Surgery. 1978;84(5):640-3

28. Hiatt WR, Regensteiner JG, Hargarten ME, Wolfel EE, Brass EP Benefit of exercise conditioning for patients with peripheral arterial disease. Circulation. 1990;81(2):602-9.

29. Radack K, Wyderski RJ. Conservative management of intermittent claudication. Ann Intern Med. 1990;113(2):135-46.

30. Ernst E, Fialka V. A review of the clinical effectiveness of exercise therapy for intermittent claudication. Arch Intern Med. 1993;153(20):2357-60

31. Ericsson B, Haeger K, Lindell SE. Effect of physical training of intermittent claudication. Angiology. 1970;21(3):188-92.

32. Lundgren F, Dahllof AG, Lundholm K, Schersten T, Volkmann R. Intermittent claudication-surgical reconstruction or physical training? A prospective randomized trial of treatment efficiency. Ann Surg. 1989;209(3):346-55 
Wolosker $\mathrm{N}$ et al.

33. Feugier P, Toursarkissian B, Chevalier JM, Favre JP; AURC. Endovascular treatment of isolated atherosclerotic stenosis of the infrarenal abdominal aorta: long-term outcome. Ann Vasc Surg. $2003 ; 17(4): 375-85$.
34. Valentine RJ, MacGillivray DC, DeNobile JW, Snyder DA, Rich NM. Intermittent claudication caused by atherosclerosis in patients aged forty years and younger. Surgery. 1990;107(5):560-5.

35. Rastogi S, Stavropoulos SW. Infrapopliteal angioplasty. Tech Vasc Interv Radiol. 2004;7(1):33-9. 